Alternative antimicrobials: the properties of fatty acids and monoglycerides.

Colin P. Churchward ${ }^{\mathrm{a}}$, Raid G. Alany ${ }^{\mathrm{a}}$, and Lori A. S. Snyder ${ }^{\mathrm{a}^{*}}$

${ }^{a}$ School of Life Sciences, Pharmacy, and Chemistry, Kingston University, Kingston upon Thames, UK

*School of Life Sciences, Pharmacy, and Chemistry, Kingston University, Kingston upon Thames, Surrey KT1 2EE, UK; l.snyder@kingston.ac.uk 


\title{
Alternative antimicrobials: the properties of fatty acids and monoglycerides.
}

\author{
With the rising antibiotic resistance of many bacterial species, alternative \\ treatments are necessary to combat infectious diseases. The World Health \\ Organisation and the U.S. Centers for Disease Control and Prevention have \\ warned that some infections, such as those from Neisseria gonorrhoeae, may be \\ untreatable within a few years. One avenue of exploration is the use of \\ antimicrobial fatty acids and their derivatives for therapeutic prevention or \\ treatment of bacterial infections. Several studies have explored the activity of \\ fatty acids and their derivatives, including monoglycerides against a variety of \\ bacterial species. These are reviewed here, assessing the antimicrobial properties \\ that have been demonstrated and the feasibility of therapeutic applications.
}

Keywords: antibacterial; antiviral; resistance; antimicrobials; infection.

\section{Introduction}

Antibiotics have saved countless lives since they were introduced, yet the spread of bacterial resistances to antibiotics necessitates investigations into other prophylaxis and treatment options. Fatty acids and there derivatives may be alternative antimicrobials worthy of investigation for the post-antibiotic era. The antimicrobial activity of fatty acids and monoglycerides has been known for over 100 years (Lamar 1911), yet the urgent need to identify alternatives in the face of growing antibiotic resistance is driving increased research in this field.

Fatty acids are amphiphilic molecules made up of saturated or unsaturated carbon chains attached to a carboxyl group. The carboxyl group is hydrophilic, while the carbon chain is hydrophobic. This gives the molecule its amphiphilic nature and means that fatty acids can act at an interface between polar and non-polar liquids to 
lower surface tension. The aqueous solubility of fatty acids is determined by the length of the non-polar carbon chain; the longer the chain the less water soluble the molecule. Fatty acids are present in all living things. In naturally occurring fatty acids, the number of carbons in the chain is usually a multiple of two, however, fatty acids with an odd number of carbons can be manufactured artificially.

Fatty acids are usually found either attached to a glycerol or a sphingosine molecule. Attached to each alcohol group on the glycerol are three fatty acids forming a triglyceride, which is important for energy storage. When broken down by lipases, the components are released, generating diglycerides, monoglycerides, glycerol and fatty acids. Phospholipids and glycolipids are essential components of cell membranes, composed of a sphingosine molecule and up to two fatty acids, where one of these fatty acids is modified.

There are some contrasting opinions on the classification of the sizes of the carbon chain and thus the descriptive classification of the various fatty acids and monoglycerides. Generally, carbon chain lengths of six or less are referred to as shortchain fatty acids, chain lengths of seven to twelve are medium-chain fatty acids, and carbon chains of 13 or greater are known as long-chain fatty acids (Osborn and Akoh 2002). The carbon chain can also vary in complexity, but only straight chain (unbranched) fatty acids will be discussed in this review.

After carbon chain length, the level of saturation of the carbon chain also has an effect on the physical properties of the molecule. Fatty acids with no double bonded carbons in their carbon chains are known as saturated fatty acids; these are the simplest fatty acids. Fatty acids that do have double carbons in their carbon chain are known as unsaturated fatty acids, as in, the carbons are not saturated with hydrogens. If only one double bond is present, then the term monounsaturated is sometimes used and fatty 
acids with more than one double bond are known as polyunsaturated. The double bond also creates another level of complexity which is manifested by giving rise to geometrical or configurational isomers (cis or trans isomers). The difference in physical properties between the two isomers is large. The trans form would make the molecule flatter, more like the straight carbon chain of an unsaturated carbon chain. The cis form on the other hand would make a more "bent" molecule. Polyunsaturated molecules with cis form double bonds therefore do not have straight carbon chains. This hinders the packing of molecules and can affect the melting temperature. The cis form of double bond is more common in nature. Although the trans form can occur in nature, it is more commonly associated with man-made processing for creating unsaturated fatty acid via hydrogenation.

\section{Antibacterial effects of fatty acids}

The antimicrobial properties of fatty acids have been reported in the scientific literature for over 100 years (Lamar 1911). With the advent of antibiotics, the antimicrobial properties of other discoveries were largely eclipsed. It was not until the 1970's that interest in fatty acids saw its antibacterial activity rediscovered with the publication of more comprehensive studies of the action of fatty acids on bacteria (Kabara and Vrable 1977). At that time, a range of Gram-positive and Gram-negative bacteria were exposed

to both saturated and unsaturated fatty acids as well as monoglycerides, other esters, and amines. It was discovered that, against the bacteria investigated, lauric acid had the most potent antimicrobial properties of the saturated fatty acids and that linoleic and linolenic acids were the most potent of the unsaturated fatty acids. These findings of the antimicrobial effects of the different types of fatty acids mirrored what had previously been discovered for soaps and detergents. However, the exact trend in antibacterial activity varied between different research studies and the action of the fatty acids was 
believed to potentially be different between different organisms.

Following on from these studies, more in-depth investigations have been conducted to try to determine the mechanism(s) of action of fatty acids and monoglycerides on particular microorganisms or specific groups of microorganisms (Miller et al. 1977; Kanetsuna 1985; Wang and Johnson 1992; Petschow et al. 1996; Bergsson et al. 1998; Bergsson et al. 1999; Bergsson et al. 2002; Sun et al. 2003; Churchward et al. 2017). These studies focused on including a greater number of bacterial strains than had been previously studied (Table 1). At the present time, while there are standard techniques used to test antimicrobial activity, such as log reduction assays that determine the ability of a substance to kill statistically significant numbers of bacteria for the substance to be considered to be effective. However, there is no standardization of the parameters used in log reduction assays, such as concentration and time. Different research investigations have used different testing conditions and techniques, where some are better at reflecting the conditions of the site of infection, such as $\mathrm{pH}$, and others are better at considering achievable concentrations and exposure times in vivo. All of experiments in Table 1 demonstrated effective killing of the bacterial species under the conditions listed, with at least a 4 log reduction in the number of bacteria following exposure to the fatty acid or monoglyceride. These different research studies have used different concentrations of fatty acids and monoglycerides, applied to the bacteria for different periods of time, in different $\mathrm{pH}$ conditions, and in different bacterial growth media, due to different growth requirements of the bacteria (Table 1). Such variations in methodology used in research in the field can hinder direct comparison of different studies.

From these studies, three candidates emerge that have demonstrated antimicrobial activity against a range of different bacterial species across several 
experiments (Figure 1). Lauric acid, a 12 carbon fatty acid has been demonstrated in several studies to be antimicrobial against Mycobacterium smegmatis, Chlamydia trachomatis, Listeria monocytogenes, Staphylococcus aureus, Neisseria gonorrhoeae, and Helicobacter pylori (Figure 1 and Table 1), which is notable considering the wide variety in surface structures of these bacterial species. The monoglyceride of lauric acid, monolaurin, is antimicrobial against some of these species, but not all (Figure 1, Table 1 ), as is the 10 carbon monoglyceride monocaprin.

\section{Antibacterial effects of monoglycerides: monocaprin or monolaurin?}

The monoglycerides monocaprin and/or monolaurin have been identified as being bactericidal in several studies (Table 1; Figure 1), however the results as to their effectiveness do not always agree. In some cases, the potency of the action of these monoglycerides has been many times greater than that of the fatty acids assayed. For example, monolaurin was shown to be over 200 times more effective at killing $S$. aureus and Streptococcus pyogenes than lauric acid, which has the same number of carbons, but lacks the glycerol present in the monoglyceride (Schlievert and Peterson 2012). Monocaprin has been demonstrated to have the fastest and most effective killing action among a panel of fatty acids and monoglycerides tested against $N$. gonorrhoeae, including monolaurin (Bergsson et al. 1999; Churchward et al. 2017). The different activity of monolaurin and monocaprin observed in the literature may be due to differences in the bacteria included in the studies, Gram-positive bacteria (Schlievert and Peterson 2012) versus Gram-negative (Bergsson et al. 1999 Churchward et al. 2017), and/or the differences could be due to differences in methodology.

In addition to the bacterial species investigated, the time that the bacteria are exposed to the fatty acids and/or monoglycerides, the temperature at which the experiment is conducted, the $\mathrm{pH}$ of the culture, and the constituents of the culture 
medium itself all vary in each study (Table 1). These differences could account for why some research finds certain fatty acids and monoglycerides more effective than others. However, if the variable of bacterial species is removed, a clearer picture emerges. Three studies by three different research groups have investigated the activity of fatty acids and monoglycerides against $H$. pylori (Table 1 ). In all three, monocaprin and monolaurin were almost equal in their bactericidal properties. Differences observed between other investigations are therefore most likely to be because one has greater activity over the other when tested against a certain bacterial species.

\section{Antiviral properties of fatty acids and monoglycerides}

The antiviral properties of a variety of fatty acids were examined in the 1980's (Kohn et al. 1980). It was demonstrated that certain fatty acids inhibited enveloped viruses such as herpes simplex, influenza, Sendai, and Sindbis viruses. However, all of the nonenveloped viruses investigated, including polio, Simian virus 40, and encephalomyocarditis virus were still active after treatment. The fatty acids found to be antiviral as a result of this research were oleic, arachidonic, and linoleic acid. Based on the experimental results, it was concluded that inactivation was due to disruption of the viral envelope, which was demonstrated by electron-micrograph (Kohn et al. 1980). In a separate study, oleic acid, linoleic acid, capric acid, lauric acid, and myristic acid were shown to also be antiviral against vesicular stomatitis virus, herpes simplex virus type 1 , and Visna virus. These viruses were also inactivated by monoglycerides monocaprylin, monocaprin, and monolaurin (Thormar et al. 1994).

The lipids present in human breast milk were shown to have antiviral activity, having the ability to inactivate enveloped viruses in a manner similar to what is seen with fatty acids (Thormar et al. 1987). This study demonstrated that the naturally 
occurring lipases in human breast milk were able to release free fatty acids and monoglycerides, contributing to the antiviral activity.

\section{Mechanism of antimicrobial action}

It remains unclear the precise mechanism of action involved in the antimicrobial properties of fatty acids and monoglycerides. Indeed, different bacteria and viruses may be inactivated via different mechanisms. A number possible targets for fatty acids and monoglycerides have been identified (Desbois and Smith 2010). After one hour of exposure to $10 \mathrm{mM}$ arachidonic acid, many morphological changes can be observed in N. gonorrhoeae and Haemophilus influenzae, including separation of inner and outer membranes, loss of cell shape, and complete cell disorganisation and disruption (Knapp and Melly 1986). This may be due to the amphiphilic nature of fatty acids and monoglycerides; at high concentrations they may act as a detergent and aid the solubilisation of the lipids in the membranes causing cell lysis. Quartz crystal microbalance-dissipation (QCM-D) and fluorescence microscopy has been applied to examine the action of lauric acid, lauryl sulfate, monolaurin, capric acid, and monocaprin on the destabilisation of the bacterial lipid bilayers that make up the bacterial cell membrane (Yoon et al. 2015; Yoon et al. 2017). These studies showed that the antimicrobials had a different effects upon the lipid bilayer, with lauric acid, lauryl sulfate, and capric acid causing tubule formation, lauryl sulfate and monocaprin ultimately causing complete bilayer solubilisation, monolaurin causing spherical protrusions from the lipid bilayer, and monocaprin causing tubules or buds. These results suggest that not all fatty acids and their derivatives disrupt bacterial membranes in the same way, even when the carbon chain lengths are the same. All tested compounds acted at or above the critical micelle concentration (CMC), with monocaprin also having an impact below the CMC where tubules are formed, as 
opposed to membrane buds (Yoon et al. 2017). The anionic surfactants, lauric acid and lauryl sulfate, produced more membrane strain than the non-ionic monolaurin, however the concentration of monolaurin needed to disturb the membrane is lower (Yoon et al. 2015). The targeting of membranes as a main mechanism of antimicrobial activity explains why fatty acids and monoglycerides have only been shown to inactivate enveloped viruses and not non-enveloped viruses.

Evidence supports the concept that the action of fatty acids and their derivatives is more than simple insertion into the bacterial membrane. Membrane remodelling is noted in the presence of docosahexaenoic acid, an unsaturated 22 carbon omega-3 fatty acid, which was used to demonstrate the utility of QCM-D for studying membrane changes (Thid et al. 2007). Often QCM-D studies use pure phospholipids, but recent studies have also investigated mixtures of phospholipids and cholesterols to investigate the influence of membrane cholesterol presence on remodelling by sodium dodecyl sulfate, lauric acid, and glycerol monolaurate (Kawakami et al. 2017). As with previous studies, the remodelling is specific to the fatty acid or derivative added, yet these results also show that it is dependent on cholesterol concentrations in the membrane as well (Kawakami et al., 2017). These results support continued research into fatty acids and monoglycerides as alternative antimicrobials.

In a study looking at food poisoning, the Gram-negative pathogen E. coli, the Gram-positive nonpathogen Staphylococcus xylosus used in creating fermented sausages, and the food spoilage yeast Zygosaccharomyces bailii were used to investigate the mode of action of monocaprylate (Hyldgaard et al. 2012). Monocaprylate integrated into the cell membranes and increased membrane permeability. It was demonstrated that the membrane fluidity and phospholipid composition of microorganisms are the key factors determining susceptibility to fatty 
acids and their derivatives (Hyldgaard et al. 2012). It is interesting to note here that $E$. coli was less susceptible to monocaprylate at $15^{\circ} \mathrm{C}$, emphasizing the importance of temperature. Both the bacterial membrane fluidity and composition and the solubility of monocaprylate will change at lower temperatures (Hyldgaard et al. 2012).

At lower concentrations, fatty acids and monoglycerides can inhibit microbial growth by preventing cell division. In this way, the antimicrobials are interfering with essential cell processes, and there are a number of theories about how. Inhibition of cell division could be due to loss of cellular contents through a membrane with increased permeability due to the fatty acids / monoglycerides. Although this does not kill the cell, the loss of material from the cell arrests division. It is also possible that cell division could be inhibited due to fatty acid / monoglyceride interaction with intracellular target(s).

Inhibition of the electron transport system, based in the inner membrane, may be responsible in part for the growth inhibition observed by $N$. gonorrhoeae when exposed to various fatty acids (Miller et al. 1977). It is hypothesized that, membrane-bound protein complexes in the inner membrane involved in the electron transport chain could be inhibited by the presence of the fatty acid / monoglyceride outside of the cell, therefore passage through the outer membrane, peptidoglycan layer, and periplasm may not be required. Fatty acids / monoglycerides could also or alternatively interfere with other membrane-bound cellular processes, such as nutrient uptake or enzyme inhibition (Desbois and Smith 2010). Another possible mechanism of action, which would require entry of the antibacterial into the cell, is the inhibition the biosynthesis of fatty acids inside the bacterial cell itself (Zheng et al. 2005; Sado-Kamdem et al. 2009). Inhibition of fatty acid biosynthesis has long been a desired target of pharmaceutical companies as 
it offers a target not used by existing antimicrobials, so there is little chance of cross resistance (Parsons and Rock 2011).

\section{Factors effecting antimicrobial activity}

The most common environmental variable that is analysed when assessing the activity of fatty acids and monoglycerides is $\mathrm{pH}$. This variable is often included in the experimental design if the particular organism of interest inhabits an environment with a low, high, or variable $\mathrm{pH}$, such as, for example, investigating the effects of fatty acids on $H$. pylori (Sun et al. 2003). There is a trend with fatty acids that generally the minimum inhibitory concentration (MIC) of shorter chain fatty acids (6-10) increase with increases in $\mathrm{pH}$ and that the MIC of medium chain fatty acids (12-14) decreases with increases in $\mathrm{pH}$. The effect of $\mathrm{pH}$ on the antimicrobial properties of longer chain fatty acids and monoglycerides is less prominent. However, monoglycerides are prone to saponification in the presence of a metal base.

Another commonly altered experimental variable is the time that the bacteria or viruses are exposed to the antimicrobial fatty acids and monoglycerides. Some research has demonstrated that fatty acids and monoglycerides have fast acting antimicrobial properties, killing in as little as one minute (Bergsson et al. 1999), while much longer incubation times are seen in other experiments. For $H$. pylori, studies using 10 minutes of incubation (Bergsson et al. 2002) gave similar levels of susceptibility to those incubated for one hour (Petschow et al. 1996). These two studies also included other experimental differences, however in the absence of a detailed pharmacodynamics study, the comparable results indicate that bactericidal activity is not heavily timedependant. This supports the theory that membrane disruption is the main cause of bactericidal activity. Cell death would be dependent on cell lysis, which would be almost instantaneous after cell membrane disruption. The concentration of freely 
available fatty acid / monoglyceride to cause cell disruption is the crucial factor in killing, rather than the amount of time exposed.

The presence of certain divalent metal ions has a pronounced effect on the action of some fatty acids. Magnesium and calcium ions were investigated for their inhibitory effects of the fatty acid on bacterial growth (Galbraith et al. 1971). Growth rates of selected Gram-positive bacteria incubated with either linoleic acid or lauric acid were observed to determine if the presence of magnesium or calcium ions could reverse the bacteriostatic effects of the fatty acids. Lauric acid had the greatest inhibitory power from the two fatty acids, but its action was reversed by the presence of magnesium or calcium ions. The mono-unsaturated linoleic acid was only affected by the action of the calcium and not by the magnesium. No such reversal by magnesium and calcium ions was observed in experiments on Mycobacterium species using various fatty acids (Kanetsuna 1985). Recent research into the use of monocaprin against ocular infections by $N$. gonorrhoeae has shown that the presence of calcium in tear fluid reduced the antibacterial properties of palmitoleic acid and linolenic acid and negated the effects of lauric acid, sodium dodecanoate, and tridecanoic acid (Churchward et al. 2017).

Serum has a strong reversal effect in some cases. In Mycobacterium species, 2\% serum reduces the action of the fatty acids by two to four times, in a $\mathrm{pH}$ dependant manner (Kanetsuna 1985). Serum was also demonstrated to reverse the effects of linolenic acid on S. aureus (Lacey and Lord 1981). Serum is known to reduce the activity of disinfectants, so its inhibition of fatty acids and monoglycerides is not surprising (Coates 1988). Some H. pylori growth media includes 5\% bovine serum, however the results obtained with such media were similar to those of other researchers (Sun et al. 2007). This suggests that the reversal effects of serum on the fatty acids may 
be complex and depends upon the fatty acid / monoglyceride being tested and / or the species of bacteria being investigated.

\section{Mechanisms of resistance}

Fatty acids and monoglycerides do not have bactericidal action against all bacterial species (Galbraith et al. 1971; Kabara and Vrable 1977). Generally speaking, more Gram-positive species are prone to their killing action than Gram-negative bacterial species. As described, the main target of the fatty acid / monoglyceride is believed to be the cell membrane, therefore, anything that prevents access to this target will inhibit their action. In Gram-positive bacteria, it has been demonstrated that Streptococcus pneumoniae is more susceptible to the bactericidal effects of fatty acids and monoglycerides than S. aureus, which is more susceptible than Bacillus subtilis (Kabara et al. 1972; Bergsson et al. 2001). These differences in susceptibility could be due to differences within the peptidoglycan layer in these three bacterial species, such as the amount of teichoic acid present, which may inhibit the action of the fatty acid / monoglyceride (Kohler et al. 2009).

Gram-negative bacteria are more likely to be resistant to the effects of fatty acids and monoglycerides, presumably due to the presence of an outer membrane. The protein content and lipopolysaccharide (LPS) structure in the outer membrane can vary greatly between different Gram-negative species (Gibson et al. 1993). Despite this, some Gramnegative bacterial species are susceptible. Neisseria (Miller et al. 1977; Knapp and Melly 1986; Bergsson et al. 1999; Churchward et al. 2017), Haemophilus (Knapp and Melly 1986; Isaacs et al. 1995; Schlievert PM, Peterson), Moraxella (Knapp and Melly 1986), Chlamydia (Bergsson et al. 1998), Helicobacter (Petschow et al. 1996; Bergsson et al. 2002; Sun et al. 2003; Sun et al. 2007; Roberton et al. 2008), and Campylobacter (Hilmarsson et al. 2006; Hermans et al. 2010; Thormar et al. 2010; Thormar et al. 2011) 
are the only Gram-negative species shown to be susceptible to fatty acids and monoglycerides. Neisseria and Haemophilus species are each susceptible to a range of fatty acids and monoglycerides and unlike the intrinsically resistant Enterobacteriaceae, have different LPS structures that may account for this susceptibility. Both Neisseria and Haemophilus lack the repeating polysaccharide O-antigen found in other Gramnegative species and instead have a highly variable and branched core oligosaccharide region. These structures are so different from other LPSs that they are often differentiated by referring to them as lipooligosaccharides (LOS) (Yamasaki et al. 1994). The LPS O-antigen of other Gram-negatives is made of a chain of hydrophilic sugars; the longer the chain the less lipophilic the outer membrane. In fact, bacteria expressing a shorter form of O-antigen are more permeable to hydrophobic antimicrobials (Tsujimoto et al. 1999).

Within the genus Neisseria, there are two pathogenic species: N. gonorrhoeae and $N$. meningitidis. These bacteria are very similar genetically but have different strategies for fatty acid / monoglyceride resistance. Both pathogens have the FarAFarB-MtrE efflux system that actively transports long chain fatty acids from the periplasmic space back outside the outer membrane (Shafer et al. 2001). The Fatty Acid Resistance (Far) efflux pump has FarA in the inner membrane and FarB in the periplasmic space, attached to FarA and also to MtrE in the outer membrane (Lee and Shafer 1999; Lee et al. 2003). This efflux system has been demonstrated to increase resistance 8 to 32 times for long chain fatty acids such as linoleic acid, oleic acid, and palmitic acid (Lee and Shafer 1999). In addition, the structure of the core oligosaccharide and hexa-acylation of its membrane anchor lipid A contributes to additional fatty acid resistance in N. meningitidis (Schielke et al. 2010). This highlights the importance of the role of the LPS / LOS structure in fatty acid / monoglyceride 
resistance in Gram-negative bacteria. Although Neisseria and Haemophilus share some features, including LOS and similar multi-drug efflux pumps, no fatty acid efflux pump has been identified in Haemophilus.

\section{Potential uses of fatty acids and monoglycerides}

Fatty acids and monoglycerides have an expansive range of possible applications in medicine, food safety, agriculture, cosmetics, and personal hygiene products (Desbois and Smith 2010; Desbois 2012). As reports around the world of multi-antibiotic resistant bacteria increase, it is evident that the time is fast approaching when key bacterial pathogens will be resistant to currently used antibiotics (Alanis 2005; Unemo et al. 2016; Jones et al. 2017). Fatty acids and monoglycerides offer alternative treatment options, either alone or in combined therapy with existing antimicrobials to improve their effectiveness. It has been shown that certain unsaturated fatty acids can act as inhibitors of bacterial conjugation, a mechanism whereby some bacteria can acquire antibiotic resistance genes (Fernandez-Lopez et al. 2005). Preventing this process by use of these unsaturated fatty acids could help reduce the spread of acquired resistance.

Fatty acids and monoglycerides may have an effect upon toxin production, a key virulence factor in some bacterial infections. Monolaurin, for example, reduces the levels of toxins produced by S. aureus (Schlievert et al. 1992; Peterson and Schlievert 2006). Topical pharmaceutical products could combine antimicrobials with mild antiseptics such as the blend of chlorhexidine dihydrochloride (antiseptic) and neomycin (antibiotic) in the nasal cream Naseptin ${ }^{\circledR}$ (Stokes and Milne 1962). Furthermore, fatty acids and monoglycerides have been shown to be synergistic with standard antimicrobials such as aminoglycosides on bacteria and even on pre- 
established bacterial biofilms (Davies and Marques, 2009; Schlievert and Peterson 2012; Hess et al. 2014; Sepehr et al. 2014).

Fatty acids and monoglycerides could also be used in the future to aid in the prevention of foodborne campylobacteriosis, food poisoning caused by Campylobacter bacteria. By adding monocaprin to feed and water of broiler chickens, the bacterial load in these birds may be reduced (Hilmarsson et al. 2006) and thereafter the poultry carcases could be washed with monocaprin (Thormar et al. 2011), as could the chopping boards and surfaces used to handle the meat (Thormar and Hilmarsson 2010). The later of these two suggestions may offer the greatest potential, as the addition of monocaprin to feed and water produced variable results and it has been shown that intestinal mucus may inhibit medium chain fatty acids and monoglycerides such as monocaprin (Hermans et al. 2010).

Potential medical treatments suggested in the research literature include a monocaprin based hydrogel for prevention of sexually transmitted bacterial infections (Thormar et al. 1999; Kristmundsdottir et al. 1999; Neyts et al. 2000; Kristmundsdottir et al. 2003), a monocaprin based cream for the treatment of viral cold sores (Thorgeirsdottir et al. 2005; Thorgeirsdottir et al. 2006), the use of fatty acids for the prevention of gastric ulcers caused by H. pylori (Roberton et al. 2008), the use of a fatty acid microemulsion against S. aureus (Butt et al. 2016), and a monocaprin or myristoleic acid eye drop against $N$. gonorrhoeae ophthalmia neonatorum infant eye infections (Churchward et al. 2017). It has been suggested that fatty acids and monoglycerides could play a valuable role in wound care (Ferreira et al. 2012). Additionally, it has been proposed that fatty acids and their cholesteryl esters could be packaged into liposomes (Cheung et al. 2016), lipid nanocapsules (Umerska et al. 
2016), or other nanotechnology formulations (Jackman et al. 2016) to enhance the activity of antibiotics.

\section{Conclusions}

It is clear that fatty acids and monoglycerides have strong antimicrobial properties that could be very useful in many applications beneficial to the health and wellbeing of humans. In particular, with the ever increasing levels of antibiotic resistance, fatty acids and monoglycerides could play a role in treatment or preventative medicine for bacterial infections. However, there are limitations to the use of fatty acids or monoglycerides including the lack of any great selective toxicity, and the reversal of antimicrobial activity by neutralising agents that may be naturally present. These factors will need to be addressed in explorations into the therapeutic application of the fatty acids and monoglycerides.

The lack of standardised methods for the investigation of fatty acids and monoglycerides has also hampered progress in this field. Some guidelines to aid in experimental design and testing of products against bacteria and viruses would aid in the interpretation of results across different studies. We suggest here that log reduction assays should be conducted at the temperature appropriate for infection of the host, demonstrating activity at the physiological temperature. A range of times from 1 minute to 24 hours should be investigated to determine how rapid killing can be achieved. The relevant physiological $\mathrm{pH}$ or range of $\mathrm{pHs}$ should be used for the log reduction assays and ideally, the activity of the fatty acid or monoglyceride against the bacteria should be determined using a media that is physiologically relevant. Most importantly, the details of the conditions under which the experiments are conducted, including temperature, time, $\mathrm{pH}$, and media composition, must be reported in the literature. By understanding 
the differences between studies, bacteria, and viruses, we may gain a better understanding of the mechanisms of action and therefore the ways in which different fatty acids and monoglycerides can be used to combat infection. The existence of registered patents describing the use of fatty acids and monoglycerides in medical products may suggest that these alternative antimicrobials will be put into application in the near future.

No potential conflict of interest was reported by the authors.

The authors report no declarations of interest.

References:

Alanis AJ. 2005. Resistance to antibiotics: are we in the post-antibiotic era? Arch Med Res 36(6):697-705.

Bergsson G, Arnfinnsson J, Karlsson SM, Steingrimsson O, Thormar H. 1998. In vitro inactivation of Chlamydia trachomatis by fatty acids and monoglycerides. Antimicrob Agents Chemother 42(9):2290-2294.

Bergsson G, Steingrimsson O, Thormar H. 1999. In vitro susceptibilities of Neisseria gonorrhoeae to fatty acids and monoglycerides. Antimicrob Agents Chemother 43(11):2790-2792.

Bergsson G, Arnfinnsson J, Steingrimsson O, Thormar H. 2001. Killing of Grampositive cocci by fatty acids and monoglycerides. APMIS 109(10):670-678.

Bergsson G, Steingrimsson O, Thormar H. 2002. Bactericidal effects of fatty acids and monoglycerides on Helicobacter pylori. Int J Antimicrob Agents 20(4):258-262.

Butt U , ElShaer A, Snyder LA, Chaidemenou A, Alany RG. 2016. Fatty acid microemulsion for the treatment of neonatal conjunctivitis: quantification, characterisation and evaluation of antimicrobial activity. Drug Deliv Transl Res 6(6):722-734. 
Churchward CP, Alany RG, Kirk RS, Walker AJ, Snyder LAS. 2017. Prevention of ophthalmia neonatorum caused by Neisseria gonorrhoeae using a fatty acid-based formulation. mBio 8:e0534-17.

Coates D. 1988. Comparison of sodium hypochlorite and sodium dichloroisocyanurate disinfectants: neutralization by serum. J Hosp Infect 11(1):60-67.

Davies DG, Marques CN. 2009. A fatty acid messenger is responsible for inducing dispersion in microbial biofilms. J Bacteriol 191:1393-1403.

Davis BD, Dubos RJ. 1947. The binding of fatty acids by serum albumin, a protective growth factor in bacteriological media. J Exp Med 86(3):215-228.

Desbois AP, Smith VJ. 2010. Antibacterial free fatty acids: activities, mechanisms of action and biotechnological potential. Appl Microbiol Biotechnol 85(6):1629-1642.

Desbois AP. 2012. Potential applications of antimicrobial fatty acids in medicine, agriculture and other industries. Recent Pat Antiinfect Drug Discov 7(2):111-122.

Fernandez-Lopez R, Machon C, Longshaw CM, Martin S, Molin S, Zechner EL, Espinosa M, Lanka E, de la Cruz F. 2005. Unsaturated fatty acids are inhibitors of bacterial conjugation. Microbiol 151(Pt 11):3517-3526.

Ferreira AM, de Souza BMV, Rigotti MA, Loureiro MRD. 2012. The use of fatty acids in wound care: An integrative review of the Brazilian literature. Rev Esc Enferm Usp 46(3):752-760.

Galbraith H, Miller TB, Paton AM, Thompson JK. 1971. Antibacterial activity of long chain fatty acids and the reversal with calcium, magnesium, ergocalciferol and cholesterol. J Appl Bacteriol 34(4):803-813.

Gibson BW, Melaugh W, Phillips NJ, Apicella MA, Campagnari AA, Griffiss JM. 1993. Investigation of the structural heterogeneity of lipooligosaccharides from pathogenic Haemophilus and Neisseria species and of R-type lipopolysaccharides from Salmonella typhimurium by electrospray mass spectrometry. J Bacteriol 175(9):27022712. 
Hermans D, Martel A, Van Deun K, Verlinden M, Van Immerseel F, Garmyn A, Messens W, Heyndrickx M, Haesebrouck F, Pasmans F. 2010. Intestinal mucus protects Campylobacter jejuni in the ceca of colonized broiler chickens against the bactericidal effects of medium-chain fatty acids. Poult Sci 89(6):1144-1155.

Hess DJ, Henry-Stanley MJ, Wells CL. 2014. Antibacterial synergy of glycerol monolaurate and aminoglycosides in Staphylococcus aureus biofilms. Antimicrob Agents Chemother 58(11):6970-6973.

Hilmarsson H, Thormar H, Thrainsson JH, Gunnarsson E, Dadadottir S. 2006. Effect of glycerol monocaprate (monocaprin) on broiler chickens: an attempt at reducing intestinal Campylobacter infection. Poult Sci 85(4):588-592.

Hyldgaard M, Sutherland DS, Sundh M, Mygind T, Meyer RL. 2012. Antimicrobial mechanism of monocaprylate. Appl Environ Microbiol 78(8):2957-2965.

Isaacs CE, Litov RE, Thormar H. 1995. Antimicrobial activity of lipids added to human milk, infant formula, and bovine milk. J Nutr Biochem 6(7):362-366.

Jackman JA, Yoon BK, Li D, Cho N-J. 2016. Nanotechnology formulations for antibacterial free fatty acids and monoglycerides. Molecules 21:305.

Jones CA, Davis JS, Looke DF. 2017. Death from an untreatable infection may signal the start of the post-antibiotic era. Med J Aust. 206(7):292-293.

Kabara JJ, Swieczkowski DM, Conley AJ, Truant JP. 1972. Fatty acids and derivatives as antimicrobial agents. Antimicrob Agents Chemother 2(1):23-28.

Kabara JJ, Vrable R. 1977. Antimicrobial lipids: natural and synthetic fatty acids and monoglycerides. Lipids 12(9):753-759.

Kawakami LM, Yoon BK, Jackman JA, Knoll W, Weiss PS, Cho N-J. 2017. Understanding how sterols regulate membrane remodelling in supported lipid bilayers. Langmuir 33(51): 14756-14765. 
Kanetsuna F. 1985. Bactericidal effect of fatty acids on mycobacteria, with particular reference to the suggested mechanism of intracellular killing. Microbiology and immunology 1985, 29(2):127-141.

Knapp HR, Melly MA. 1986. Bactericidal effects of polyunsaturated fatty acids. J Infect Dis 154(1):84-94.

Kohler T, Weidenmaier C, Peschel A. 2009. Wall teichoic acid protects Staphylococcus aureus against antimicrobial fatty acids from human skin. J Bacteriol 191(13):44824484.

Kohn A, Gitelman J, Inbar M. 1980. Unsaturated free fatty acids inactivate animal enveloped viruses. Arch Virol 66(4):301-307.

Kristmundsdottir T, Arnadottir SG, Bergsson G, Thormar H. 1999. Development and evaluation of microbicidal hydrogels containing monoglyceride as the active ingredient. J Pharm Sci 88(10):1011-1015.

Kristmundsdottir T, Sigurdsson P, Thormar H. 2003. Effect of buffers on the properties of microbicidal hydrogels containing monoglyceride as the active ingredient. Drug Devel Ind Pharm 29(2):121-129.

Lacey RW, Lord VL. 1981. Sensitivity of staphylococci to fatty acids: novel inactivation of linolenic acid by serum. J Med Microbiol 14(1):41-49.

Lamar RV. 1911. Chemo-immunological studies on localized infections : Second Paper: Lysis of the pneumococcus and hemolysis by certain fatty acids and their alkali soaps. $\mathrm{J}$ Exp Med 13(3):380-386.

Lee EH, Shafer WM. 1999. The farAB-encoded efflux pump mediates resistance of gonococci to long-chained antibacterial fatty acids. Mol Microbiol 33(4):839-845.

Lee EH, Rouquette-Loughlin C, Folster JP, Shafer WM. 2003. FarR regulates the farAB-encoded efflux pump of Neisseria gonorrhoeae via an MtrR regulatory mechanism. J Bacteriol 185(24):7145-7152.

Miller RD, Brown KE, Morse SA. 1977. Inhibitory action of fatty acids on the growth of Neisseria gonorrhoeae. Infect Immun 17(2):303-312. 
Neyts J, Kristmundsdottir T, De Clercq E, Thormar H. 2000. Hydrogels containing monocaprin prevent intravaginal and intracutaneous infections with HSV-2 in mice: impact on the search for vaginal microbicides. J Med Virol 61(1):107-110.

Osborn HT, Akoh CC. 2002. Structured lipids-novel fats with medical, nutraceutical, and food applications. Compr Rev Food Sci Food Saf. 1(3):110-120.

Parsons JB, Rock CO. 2011. Is bacterial fatty acid synthesis a valid target for antibacterial drug discovery? Curr Opin Microbiol 14(5):544-549.

Peterson ML, Schlievert PM. 2006. Glycerol monolaurate inhibits the effects of Grampositive select agents on eukaryotic cells. Biochemistry 45(7):2387-2397.

Petschow BW, Batema RP, Ford LL. 1996. Susceptibility of Helicobacter pylori to bactericidal properties of medium-chain monoglycerides and free fatty acids. Antimicrob Agents Chemother 40(2):302-306.

Roberton AM, O'Connor CJ, Martin IG, Alany RG. 2008. Gastric therapies and compositions thereof. In.: Google Patents; 2008.

Sado-Kamdem SL, Vannini L, Guerzoni ME. 2009. Effect of alpha-linolenic, capric and lauric acid on the fatty acid biosynthesis in Staphylococcus aureus. Int J Food Microbiol 129(3):288-294.

Schielke S, Schmitt C, Spatz C, Frosch M, Schubert-Unkmeir A, Kurzai O. 2010. The transcriptional repressor FarR is not involved in meningococcal fatty acid resistance mediated by the FarAB efflux pump and dependent on lipopolysaccharide structure. Appl Environ Microbiol 76(10):3160-3169.

Schlievert PM, Deringer JR, Kim MH, Projan SJ, Novick RP. 1992. Effect of glycerol monolaurate on bacterial growth and toxin production. Antimicrob Agents Chemother 36(3):626-631.

Schlievert PM, Peterson ML. 2012. Glycerol monolaurate antibacterial activity in broth and biofilm cultures. PLoS One 7(7):e40350. 
Sepehr S, Rahmani-Badi A, Babaie-Naiej H, Soudi MR. 2014. Unsaturated fatty acid, cis-2-decenoic acid, in combination with disinfectants or antibiotics removes preestablished biofilms formed by food-related bacteria. PLoS One 9(7):e101677.

Shafer WM, Veal WL, Lee EH, Zarantonelli L, Balthazar JT, Rouquette C. 2001. Genetic organization and regulation of antimicrobial efflux systems possessed by Neisseria gonorrhoeae and Neisseria meningitidis. J Mol Microbiol Biotechnol 3(2):219-224.

Stokes EJ, Milne SE. 1962. Effect of Naseptin cream prophylaxis on staphylococcal infection in adult surgical wards and infant nurseries. J Hyg (Lond) 60:209-15.

Sun CQ, O'Connor CJ, Roberton AM. 2003 Antibacterial actions of fatty acids and monoglycerides against Helicobacter pylori. FEMS Immunol Med Microbiol 36(1-2):917.

Sun CQ, O'Connor CJ, MacGibbon AK, Roberton AM. 2007. The products from lipasecatalysed hydrolysis of bovine milkfat kill Helicobacter pylori in vitro. FEMS Immunol Med Microbiol 49(2):235-242.

Thid D, Benkoski JJ, Svedhem S, Kasemo B, Gold J. 2007. DHA-induced changes of supported lipid membrane morphology. Langmuir 23(11):5878-5881.

Thorgeirsdottir TO, Hilmarsson H, Thormar H, Kristmundsdottir T. 2005. Development of a virucidal cream containing the monoglyceride monocaprin. Die Pharmazie 60(12):897-899.

Thorgeirsdottir TO, Thormar H, Kristmundsdottir T. 2006. Viscoelastic properties of a virucidal cream containing the monoglyceride monocaprin: effects of formulation variables: a technical note. AAPS Pharm Sci Tech 7(2):E44.

Thormar H, Isaacs CE, Brown HR, Barshatzky MR, Pessolano T. 1987. Inactivation of enveloped viruses and killing of cells by fatty acids and monoglycerides. Antimicrob Agents Chemother 31(1):27-31. 
Thormar H1, Isaacs CE, Kim KS, Brown HR. 1994. Inactivation of visna virus and other enveloped viruses by free fatty acids and monoglycerides. Ann N Y Acad Sci. 1994 Jun 6;724:465-71.

Thormar H, Bergsson G, Gunnarsson E, Georgsson G, Witvrouw M, Steingrimsson O, De Clercq E, Kristmundsdottir T. 1999. Hydrogels containing monocaprin have potent microbicidal activities against sexually transmitted viruses and bacteria in vitro. Sex Transm Infect 75(3):181-185.

Thormar H, Hilmarsson H. 2010. Killing of Campylobacter on contaminated plastic and wooden cutting boards by glycerol monocaprate (monocaprin). Lett Appl Microbiol 51(3):319-324.

Thormar H, Hilmarsson H, Thrainsson JH, Georgsson F, Gunnarsson E, Dadadottir S. 2011. Treatment of fresh poultry carcases with emulsions of glycerol monocaprate (monocaprin) to reduce contamination with Campylobacter and psychrotrophic bacteria. Brit Poult Sci 52(1):11-19.

Tsujimoto H, Gotoh N, Nishino T. 1999. Diffusion of macrolide antibiotics through the outer membrane of Moraxella catarrhalis. J Infect Chemother 5(4):196-200.

Umerska A, Cassisa V, Matougui N, Joly-Guillou ML, Eveillard M, Saulnier P. 2016. Antibacterial action of lipid nanocapsules containing fatty acids or monoglycerides as co-surfactants. Eur J Pharm Biopharm 108:100-110.

Unemo M, Del Rio C, Shafer WM. 2016. Antimicrobial Resistance Expressed by Neisseria gonorrhoeae: A Major Global Public Health Problem in the 21st Century. Microbiol Spectr 4(3).

Wang LL, Johnson EA. 1992. Inhibition of Listeria monocytogenes by fatty acids and monoglycerides. Appl Environ Microbiol 58(2):624-629.

Yamasaki R, Kerwood DE, Schneider H, Quinn KP, Griffiss JM, Mandrell RE. 1994. The structure of lipooligosaccharide produced by Neisseria gonorrhoeae, strain 15253, 
isolated from a patient with disseminated infection. Evidence for a new glycosylation pathway of the gonococcal lipooligosaccharide. J Biol Chem 269(48):30345-30351.

Yoon BK, Jackman JA, Kim MC, Cho NJ. 2015. Spectrum of membrane morphological responses to antibacterial fatty acids and related surfactants. Langmuir 31(37):1022310232.

Yoon BK, Jackman JA, Kim MC, Sut TN, Cho NJ. 2017. Correlating membrane morphological responses with micellar aggregation behavior of capric acid and monocaprin. Langmuir 33(11): 2750-2759.

Zheng CJ, Yoo JS, Lee TG, Cho HY, Kim YH, Kim WG. 2005. Fatty acid synthesis is a target for antibacterial activity of unsaturated fatty acids. FEBS Lett 579(23):51575162. 
Table 1 . Antibacterial killing activity of fatty acids and monoglycerides at $37^{\circ} \mathrm{C}$.

\begin{tabular}{|c|c|c|c|}
\hline Organism & $\begin{array}{l}\text { Most effective } \\
\text { fatty acid or } \\
\text { monoglyceride }\end{array}$ & $\begin{array}{l}\text { Log reduction assay } \\
\text { conditions, demonstrating } \\
\text { bacterial killing }\end{array}$ & Reference \\
\hline $\begin{array}{l}\text { Chlamydia } \\
\text { trachomatis }\end{array}$ & $\begin{array}{l}\text { Capric acid } \\
\text { Lauric acid } \\
\text { Monocaprin }\end{array}$ & $\begin{array}{l}20 \mathrm{mM} \text { for } 5 \text { minutes } \\
10 \mathrm{mM} \text { for } 10 \text { minutes } \\
5 \mathrm{mM} \text { for } 5 \text { minutes }\end{array}$ & $\begin{array}{l}\text { Bergsson et } \\
\text { al. } 1998\end{array}$ \\
\hline \multirow[t]{3}{*}{ Helicobacter pylori } & $\begin{array}{l}\text { Lauric acid } \\
\text { Monocaprin } \\
\text { Monolaurin } \\
\text { Monocaprylin }\end{array}$ & $\begin{array}{l}1 \mathrm{mM} \text { for } 1 \text { hour } \\
1 \mathrm{mM} \text { for } 1 \text { hour } \\
1 \mathrm{mM} \text { for } 1 \text { hour } \\
5 \mathrm{mM} \text { for } 1 \text { hour }\end{array}$ & $\begin{array}{l}\text { Petschow et } \\
\text { al. } 1996\end{array}$ \\
\hline & $\begin{array}{l}\text { Lauric acid } \\
\text { Linolenic acid } \\
\text { Monolaurin } \\
\text { Monomyristin }\end{array}$ & $\begin{array}{l}1 \mathrm{mM} \text { for } 40 \text { minutes* } \\
0.5 \mathrm{mM} \text { for } 40 \text { minutes* } \\
0.5 \mathrm{mM} \text { for } 40 \text { minutes* } \\
0.9 \mathrm{mM} \text { for } 40 \text { minutes* }\end{array}$ & $\begin{array}{l}\text { Sun et al. } \\
2003\end{array}$ \\
\hline & $\begin{array}{l}\text { Lauric acid } \\
\text { Palmitoleic acid } \\
\text { Monocaprin } \\
\text { Monolaurin }\end{array}$ & $\begin{array}{l}1.25 \mathrm{mM} \text { for } 10 \text { minutes } \\
1.25 \mathrm{mM} \text { for } 10 \text { minutes } \\
1.25 \mathrm{mM} \text { for } 1 \text { minutes } \\
1.25 \mathrm{mM} \text { for } 1 \text { minutes }\end{array}$ & $\begin{array}{l}\text { Bergsson et } \\
\text { al. } 2002\end{array}$ \\
\hline $\begin{array}{l}\text { Listeria } \\
\text { monocytogenes }\end{array}$ & $\begin{array}{l}\text { Lauric acid } \\
\text { Linolenic acid } \\
\text { Monolaurin }\end{array}$ & $\begin{array}{l}20 \mu \mathrm{g} / \mathrm{ml} \text { for } 24 \text { hours }{ }^{\prime} \\
10 \mu \mathrm{g} / \mathrm{ml} \text { for } 24 \text { hours } \ddagger \\
100 \mu \mathrm{g} / \mathrm{ml} \text { for } 24 \text { hours } \dagger \\
20 \mu \mathrm{g} / \mathrm{ml} \text { for } 24 \text { hours } \ddagger \\
10 \mu \mathrm{g} / \mathrm{ml} \text { for } 24 \text { hours }{ }^{\prime} \\
10 \mu \mathrm{g} / \mathrm{ml} \text { for } 24 \text { hours } \ddagger\end{array}$ & $\begin{array}{l}\text { Wang and } \\
\text { Johnson } \\
1992\end{array}$ \\
\hline $\begin{array}{l}\text { Mycobacterium } \\
\text { smegmatis }\end{array}$ & $\begin{array}{l}\text { Lauric acid } \\
\text { Myristic acid }\end{array}$ & $\begin{array}{l}0.2 \mathrm{mM} \text { for } 20 \text { minutes } \ddagger \\
0.2 \mathrm{mM} \text { for } 20 \text { minutes }{ }^{\wedge}\end{array}$ & $\begin{array}{l}\text { Kanetsuna } \\
1985\end{array}$ \\
\hline
\end{tabular}




\begin{tabular}{|c|c|c|c|}
\hline & $\begin{array}{l}\text { Palmitoleic acid } \\
\text { Oleic acid }\end{array}$ & $\begin{array}{l}0.2 \mathrm{mM} \text { for } 20 \text { minutes }{ }^{\wedge} \\
0.1 \mathrm{mM} \text { for } 20 \text { minutes }{ }^{\wedge}\end{array}$ & \\
\hline $\begin{array}{l}\text { Neisseria } \\
\text { gonorrhoeae }\end{array}$ & $\begin{array}{l}\text { Lauric acid } \\
\text { Palmitoleic acid } \\
\text { Monocaprin } \\
\text { Monolaurin }\end{array}$ & $\begin{array}{l}2.5 \mathrm{mM} \text { for } 1 \text { minute } \\
2.5 \mathrm{mM} \text { for } 1 \text { minute } \\
2.5 \mathrm{mM} \text { for } 1 \text { minute } \\
2.5 \mathrm{mM} \text { for } 1 \text { minute }\end{array}$ & $\begin{array}{l}\text { Bergsson et } \\
\text { al. } 1999\end{array}$ \\
\hline & $\begin{array}{l}\text { Myristoleic acid } \\
\text { Palmitoleic acid } \\
\text { Linolenic acid } \\
\text { Monocaprin }\end{array}$ & $\begin{array}{l}0.5 \mathrm{mM} \text { for } 2 \text { minutes } \\
0.5 \mathrm{mM} \text { for } 2 \text { minutes } \\
0.5 \mathrm{mM} \text { for } 2 \text { minutes } \\
0.5 \mathrm{mM} \text { for } 2 \text { minutes }\end{array}$ & $\begin{array}{l}\text { Churchward } \\
\text { et al. } 2017\end{array}$ \\
\hline $\begin{array}{l}\text { Staphylococcus } \\
\text { aureus }\end{array}$ & $\begin{array}{l}\text { Lauric acid } \\
\text { Monolaurin }\end{array}$ & $\begin{array}{l}0.25 \mathrm{mM} \text { for } 24 \text { hours } \\
0.25 \mathrm{mM} \text { for } 24 \text { hours }\end{array}$ & $\begin{array}{l}\text { Schlievert } \\
\text { and } \\
\text { Peterson } \\
2012\end{array}$ \\
\hline
\end{tabular}

$\sim$ Conditions under which log reduction assays were conducted and for which there was at least a 4 log reduction in viable bacteria, the standard for effective bacterial killing.

* Conducted at $37{ }^{\circ} \mathrm{C} \mathrm{pH} 7.4$ in medium containing $5 \%$ horse serum.

† Conducted at $\mathrm{pH} 6.0$.

$\ddagger$ Conducted at $\mathrm{pH}$ 5.0.

$\wedge$ Conducted at $\mathrm{pH}$ 7.0. 


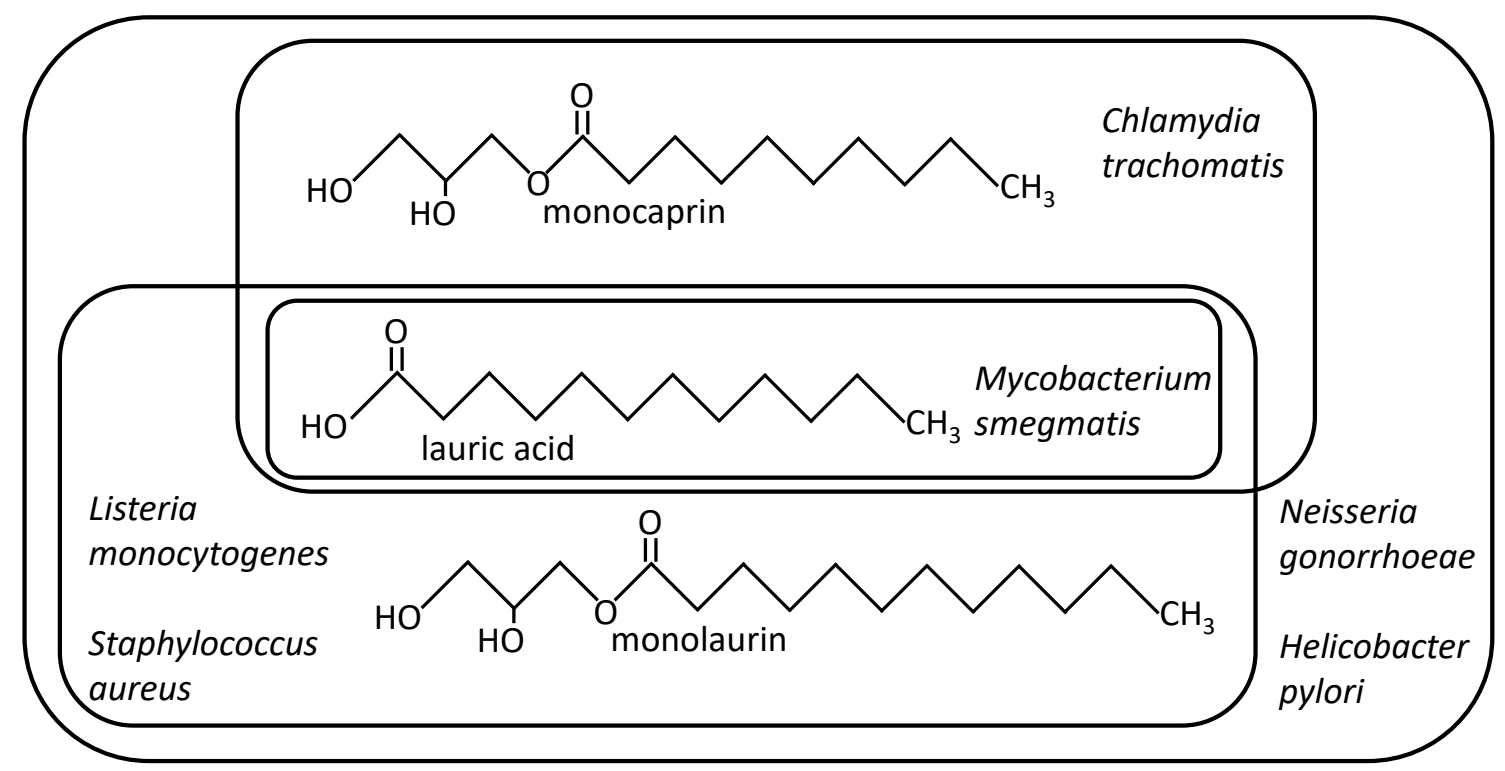

Figure 1. Activity of antimicrobial fatty acid and monoglycerides against bacteria species. Shown here are the structures of the antimicrobial fatty acid lauric acid, its monoglyceride monolaurin and the monoglyceride of capric acid, monocaprin, which are frequently investigated for antibacterial killing activity (see Table 1). These have overlapping antimicrobial activity against unrelated bacterial species, as shown, with all three being active against Neisseria gonorrhoeae and Helicobacter pylori, monolaurin also being active against Staphylococcus aureus and Listeria monocytogenes, monocaprin also being active against Chlamydia trachomatis, and lauric acid being effective at killing all of these bacteria and also Mycobacterium smegmatis. 